\title{
Active Immunization Of Rabbit With Gamma Irradiated Cobra (Naja haje) Venom Toxoid
}

\author{
Esmat A. Shaban \\ Department of Drug Radiation Research and Technology, \\ Atomic Energy Authority
}

\begin{abstract}
Cobra (Naja haje) venom detoxified by gamma radiation (15KGy or $25 \mathrm{KGy})$ was used as toxoid for active immunization of rabbits following a short schedule ( on day $0,7,21$ ) of immunization with complete Freund's adjuvant. Effective neutralization of venom toxin by immune sera of rabbits was observed. The presence of antibody in the immune sera was detected by immuno-diffusion test. The non-irradiated and the two dose levels gamma irradiated Naja haje venom, against the antivenin antibody produced with non-irradiated venom or against antivenin antibody produced with $15 \mathrm{KGy}$ gamma irradiated venom all showed similar patterns. Also there was no change in the titer of antivenin solution obtained from the rabbit immunized with $15 \mathrm{KGy}$ irradiated venom, as compared with that antivenin solution obtained from rabbit immunized with non-irradiated venom. Sera of rabbits immunized with $15 \mathrm{KGy}$ irradiated venom toxoid (15KGy toxoid antiserum) neutralized venom lethality, 95\% of protease activity and $50 \%$ of phospholipase A2.
\end{abstract}

\section{Introduction}

Cobra (Naja haje) is one of the major causes of snake bites death in Egypt. Detoxified venoms can be used to produce antiserum as an effort to protect the animals from the venom toxicity. Detoxification of antigen or toxoid production requires that venom loses its toxicity, but at the same time retains maximum immunogenicity (Khan et al., 1977). Several techniques have been used to detoxify venom such as: treatment with formaldehyde (Khan et al. 1977), glutaraldehyde (Guidolin et al., 1989), and iodine (Rocha et al., 1992). Linking carboxymethyl-cellulose (Moroz et al.1963), functional group blockage (Chicheportiche et al., 1972), and by encapsulation in lyosomes (Freitas and Frezard 1997). One method that has been shown to be effective for attenuating venom toxicity and maintaining immunogenicity is gamma radiation (Nascimento et al., 1996). An effective toxoid against Russell's Viper venom was developed by gamma irradiation which yielded a potent antivenom (in rabbits without adjuvant) capable of neutralizing lethal, protease and phosphodiesterase activities of the crude venom ( Hati et al., 1990). Shaban (1990) also, developed a toxoid by gamma irradiation against Androctonus amoreuxi scorpion venom which produce a potent antivenom (in rabbits with complete Freund's adjuvant) which neutralize venom lethality as well as some biochemical and pharmacological venom toxicities. Preliminary experiments with Naja haje venom (Shaban et al., 1996) showed that the lethality of Naja haje venom irradiated in the dry form was not affected up to a dose of $100 \mathrm{KGy}$. On the other hand, the venom irradiated in the aqueous solution form showed a decrease in lethality while the ability of the venom antigens to react with its corresponding antibodies was retained up to irradiation dose of 50KGy. Effective toxoids against (Naja haje and Cerastes cerastes) snake venom, were developed by Shaban (2003) using gamma irradiation (15 KGy). The toxoids obtained are devoided of toxicity while retaining their antigenicity. 
In the present study immunization of rabbits with gamma irradiated Naja haje venom toxoid was carried out The neutralization capacities of the immune sera against lethality, phospholipase and protease activity of the Cobra (Naja haje) venom was studied.

\section{Material and Methods}

Animals:

Male albino Swiss mice weighing between 18-20g and male rabbits weighing about $3.5 \mathrm{Kg}$ were used in this study. Animals were maintained under standard conditions of boarding and given standard food libitum.

Venom:

Pooled venom of Naja haje (Egyptian Cobra) was obtained from serpentarium of the Medical Research Center, Faculty of Medicine, Ain Shams University extracted from healthy snake by milking, dried and lyophilized kept in desiccators at $4^{\circ}$ till used.

Detoxification:

Gamma irradiation of Cobra venom was carried out at the National Center for Research and Radiation Technology, Cairo, Egypt, using cobalt 60 gamma cell 220, manufactured by the atomic energy of Canada (AECL). The radiation dose rate was 1.4 rad per second.

Samples of Cobra venom in solution were subjected to 25 and $15 \mathrm{KGy}$ respectively. A non- irradiated sample of crude venom was used as control.

Lethality Assay:

Median lethal dose LD50 of the crude Cobra (Naja haje) venom and gamma irradiated venom (15KGy and 25KGy) were determined by i.p. injection into mice according to Spearnam Karber method (WHO1981).

Hyper immunization of rabbits:

Male rabbits weighing 3-3.5 kg were used . The rabbits were injected subcutaneously with venom each dose being emulsified in $0.5 \mathrm{ml}$ complete Freund's adjuvant
(Defico. Laboratories, Detroit, Mich.) According to the following schedule : one injection of $200 \mu \mathrm{g}$ in the first, seven and twenty one day respectively. A booster without adjuvant was given one week later. Six days the animals were bled. The same schedule was repeated using $15 \mathrm{KGy}$ gamma irradiated venom in two different doses $200 \mu \mathrm{g}$ and $1000 \mu \mathrm{g}$ as well as 25KGy $(200 \mu \mathrm{g})$ gamma irradiated venom . Pooled sera of two immunized rabbits for each set of immunization were used.

Immunodiffusion technique:

Immunodiffusion experiment was carried out according to the method described by Ouchterlony and Nelsson (1978) on glass slides $(5 \times 5 \mathrm{~cm})$ using $1.2 \%$ Noble agar (Defico. Laboratories, Detroit, Mich.) in $0.9 \%$ Nacl solution. Sodium azide in a concentration of $0.05 \%$ was added to retard bacterial growth. The wells were filled with $20 \mu \mathrm{l}$ volumes of either the rabbit antiserum raised against nonirradiated or $15 \mathrm{KGy}$ irradiated venom. After developing of the precipitin bands (48 $\mathrm{hrs}$ at $25^{\circ} \mathrm{c}$ ), the plates were washed for 24 hrs in saline dried and stained with amidoschwartz $10 \mathrm{~B}(0.5 \%$ in $5 \%$ acetic acid) for $7 \mathrm{~min}$. washed with methanol acetic acid (9:1), dried in air and photographed.

Titer determination:

Using double diffusion experiments, the titer of the antibody from the animal, immunized with $15 \mathrm{KGy}$ irradiated venom, was compared to that of the animal immunized with non-irradiated venom.

A serial dilution of the antivenin, to be tested, was obtained using $0.9 \%$ Normal saline, as diluents. $20 \mu \mathrm{l}$ of Naja haje venom solution of $20 \mathrm{mg} / \mathrm{ml}$, was placed in the central well while in the six peripheral wells serial dilutions of the antivenin solution to be tested, were placed. After the incubation of the slides (20- $72 \mathrm{hrs}$ ), they were treated as Ouchterlony.

The titer of each sample is defined as: the reciprocal of the highest dilution giving a positive precipitin bands with Naja haje venom $(20 \mathrm{mg} / \mathrm{ml})$ (Tizard 1984). 
Venom neutralization test:

In this experiment Naja haje venom was incubated with the specific antivenin for one hour at $37^{\circ} \mathrm{c}$ in the proportion of $1 \mathrm{ml}$ serum to $10 \mathrm{LD} 50$.

Protection against venom lethality in mice:

The venom antivenin mixture was shaken and dose equal the LD50 $\quad(5 \mu \mathrm{g} / 20 \mathrm{~g}$ mouse) was injected into each of 10 mice. Doses of the incubated mixture equal 25times the LD50 were injected each into a group of 10mice. All mice were observed for $24 \mathrm{hrs}$ after injection.

Assay of venom enzymes:

Phospholipase A2 activity: it was assayed according to the method of Desnuelle et al., (1995) and Nieuwenhuizen et al., (1974). Lecithin was used as substrate, and was solubulised either with sodium cholate or triton X-100. the enzymes activity measured at A558mn. The phospholipase A2 was determined as corresponding to the decrease in O.D.

Proteolytic activity: The method by Labib et al., (1980 was followed for proteolytic activity using casein as substrate. The enzyme activity measured at A280.

Neutralization of Phospholipase and proteolytic activity:

Varying amount of antiserum were preincubated with $5 \mu \mathrm{l}(25 \mu \mathrm{g})$ crude venom in a volume of $0.1 \mathrm{ml}$ for one hour at $37{ }^{\circ} \mathrm{C}$. Enzymes activities of the mixture were assayed as described earlier. Control experiments were carried out by using normal rabbit serum.

\section{$\underline{\text { Results: }}$}

\section{Lethality assay:}

The i.p. LD50 for non irradiated, 15KGy and $25 \mathrm{KGy}$ Naja haje venom were estimated to be $5 \mu \mathrm{g} / 20 \mathrm{~g}$ mouse, $16 \mu \mathrm{g} / 20 \mathrm{~g}$ mouse and $50 \mu \mathrm{g} / 20 \mathrm{~g}$ mouse respectively.

$15 \mathrm{KGY}$ irradiated venom toxoid $(200 \mu \mathrm{g})$ and $(1000 \mu \mathrm{g})$ as well as $25 \mathrm{KGy}$ irradiated venom toxoid produced antitoxin in rabbit sera after injection of three doses ( on day $0,7,21$ and a booster dose) as revealed by neutralization test in mice. Incubation of Naja haje venom with the specific antivenin (obtained from nonirradiated venom toxoid or gamma irradiated venom toxoid) protected the mice against the lethal action of a dose of the venom equivalent to three fold the LD50. It also protects $80 \%$ of the mice against the lethal action of the dose of the venom equivalent to 4 times the LD50.

Injection of higher dose of $15 \mathrm{KGy}$ venom toxoid $(1000 \mu \mathrm{g})$ had little detrimental effect on the experimental animals yet did not result in higher neutralization power against venom lethality.

\section{Determination of antivenin titer:}

There was no change in the titer of antivenin solution obtained from the rabbits immunized with $15 \mathrm{KGy}$ irradiated venom toxoid, as compared with that of antivenin solution obtained from rabbits immunized with non- irradiated venom toxoid. (fig.1). Using the immunodiffusion experiment definite precipitin bands were obtained with a venom concentration of $20 \mathrm{mg} / \mathrm{ml}$, and serum dilution up to $1: 32$ 


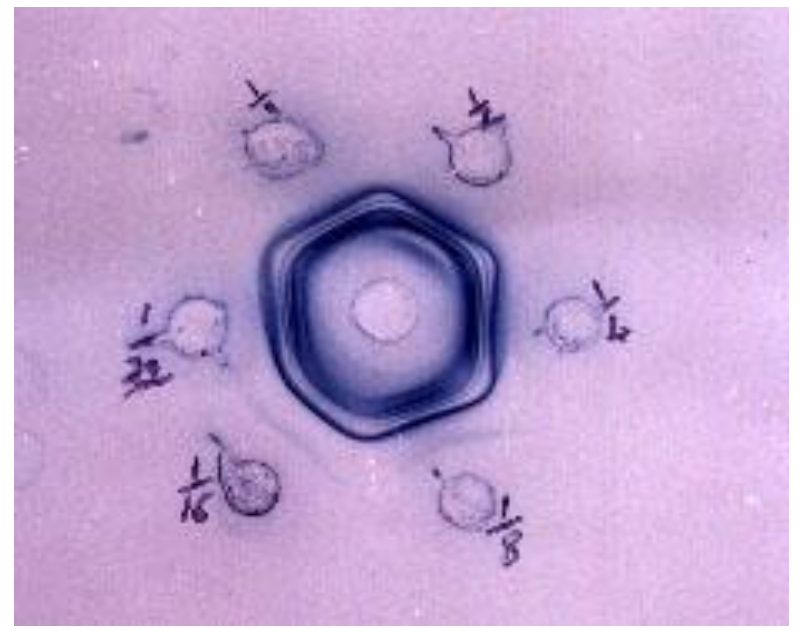

Fig.1 : Determination of titer of antibody using double diffusion reaction.

Ve: non-irradiated venom (in the central well)

In peripheral wells, rabbit serum antivenin raised against $15 \mathrm{KGy}$ irradiated venom, serially diluted up to $1: 32$

\section{Double diffusion technique:}

Immunodiffusion test (fig.2\&3) demonstrated the presence of several antibodies in the immunized sera of rabbits. Multiple precipitin bands were observed in $15 \mathrm{KGY}$ and 25KGy toxoid antisera. Inimmunodiffusion test antivenoms raised against non-

irradiated, $15 \mathrm{KGy}$ and 25KGy gamma irradiated venom, showed similar results. The visible lines were identical and were joined smoothly at the corners, indicating that, they have the same antigenic determinant.

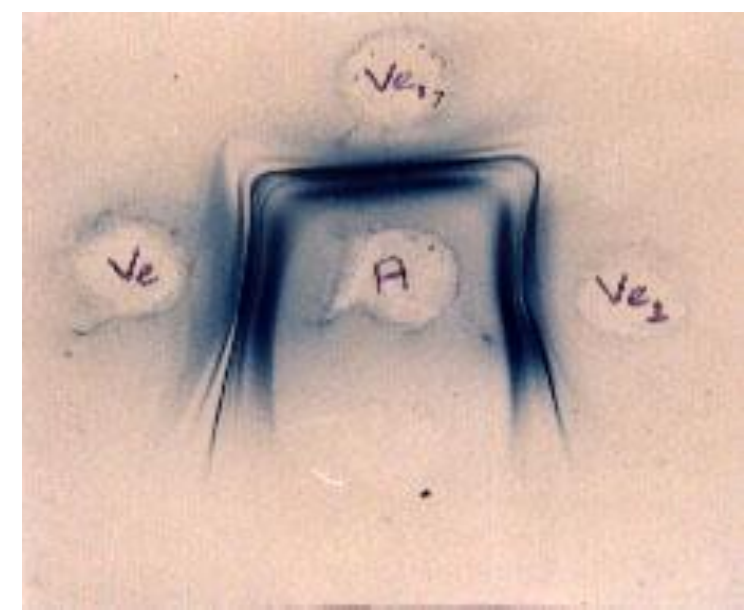

Fig.2 : Double diffusion reaction of rabbit serum antivenin from non-irradiated Naja haje venom ( central well) with non-irradiated and gamma irradiated venom.

Ve: non-irradiated venom $(20 \mathrm{mg} / \mathrm{ml})$.

Ve1: $15 \mathrm{KGy}$ gamma irradiated venom $(20 \mathrm{mg} / \mathrm{ml})$.

Ve2: $25 \mathrm{KGy}$ gamma irradiated venom $(20 \mathrm{mg} / \mathrm{ml})$. 


\section{Esmat A. Shaban}

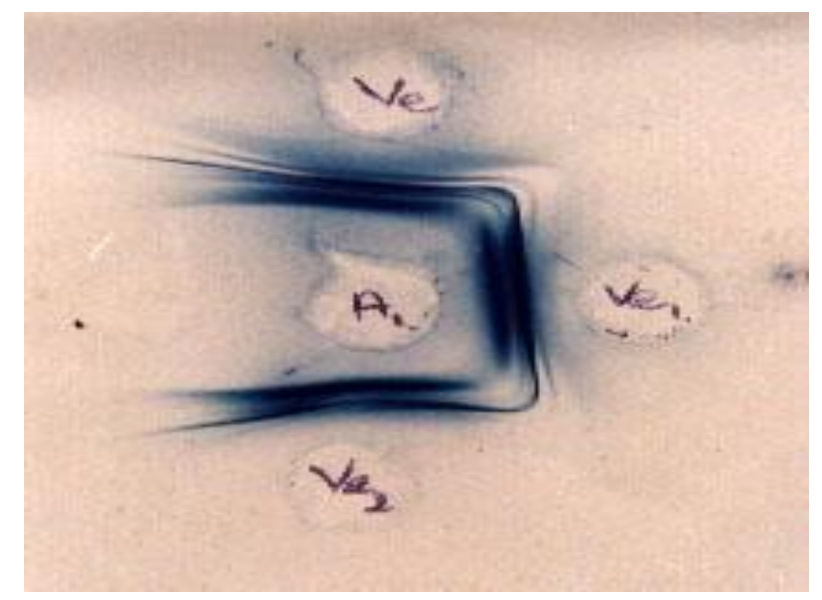

Fig. 3: Double diffusion reaction of rabbit serum antivenin from $15 \mathrm{KGy}$ irradiated venom (central well) with non-irradiated venom and gamma irradiated venom.

Ve: non-irradiated venom $(20 \mathrm{mg} / \mathrm{ml})$.

Ve1: $15 \mathrm{KGy}$ gamma irradiated venom $(20 \mathrm{mg} / \mathrm{ml})$.

Ve2: $25 \mathrm{KGy}$ gamma irradiated venom $(20 \mathrm{mg} / \mathrm{ml})$.

\section{Neutralization of phospholipase and proteolytic activities:}

A significant inhibition of both phospholipase A2 and protease activities was obtained when neutralized with $15 \mathrm{KGy}$ irradiated venom toxoid. (Fig.4).

(A)

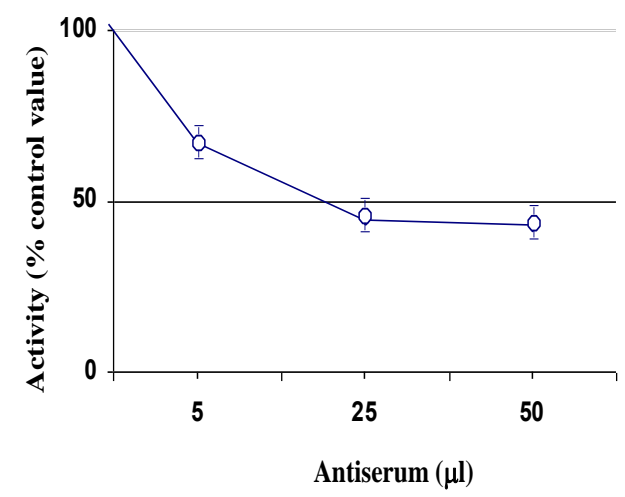

(B)

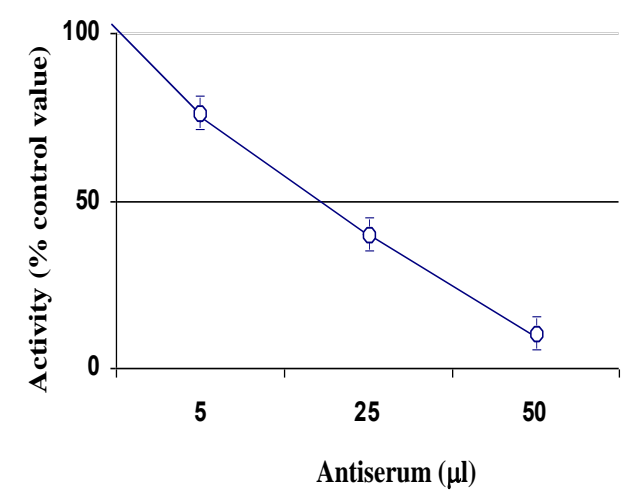

Fig 4 : Neutralization of phospholipase $\mathrm{A}_{2}$ and protease activities of crude venom by immune sera .

Percent of control values of enzyme activities in presence of varying amounts of immune sera were calculated from the value $(100 \%)$ obtained by incubating venom with corresponding amount of normal sera. Control $(100 \%)$ activities for phospholpase and protease were 1.8 O.D. at $558 \mathrm{~nm}$ and 0.10 O.D. at $280 \mathrm{~nm}$ respectively. Control values present the mean value of three sets of experiment; $25 \mu \mathrm{g}$ of protein was used in the assay of each enzyme. (a) Phospholipase A2 ; (b) protease.-o- $15 \mathrm{KGy}$ toxoid antiserum. Data are mean of + S.E.M. of three separate determination. 


\section{Discussion}

Our study describes the active immunization of rabbits by gamma irradiated Cobra Naja haje venom toxoid. Effect of ionizing radiation on the proteins and peptides in aqueous solution is mediated either directly or indirectly (Alexender, 1960). In a direct effect several reactive species such as $\mathrm{O}_{-2}, \mathrm{e}_{\text {-aq }}, \mathrm{H}$ and $\mathrm{oH}$ formed from the radiolysis of water react rapidly with a large variety of biological molecule, although the reaction may be specific to a certain site or group in the molecules. The production of different antibodies in the immune sera of rabbits (Fig. 2) demonstrated that antigenicity of some components of venom was retained in the toxoid used in the study.

Experimental evidence suggests that neutralization of lethal effect of venom by antisera may not correlate with the neutralization of pathopharmacological effect (Gene et.al, 1985). Standardization of antivenoms based on the neutralization of specific pathopharmacological effects has been recommended by the World Health Organization (WHO, 1981). Several enzymes in the venom may be responsible for some of its pathopharmacological effects (Warrell, 1987; Jimenez-porras, 1968).

The $\mathrm{LD}_{50}$ values for natural venom and the two dose levels irradiated venom were $5 \mu \mathrm{g} /$ mouce, $16 \mu \mathrm{g} /$ mouce, and 50 $\mu \mathrm{g} /$ mouse, respectively. The $\mathrm{LD}_{50}$ for 15 KGy and 25 KGy irradiated venom were 3.2 times and 10 times less toxic than natural venom, respectively. Similar results were reported by other authors, Murata et al. (1990) and Clissa et al (1999), who suggested that toxicity of irradiated venom would be reduced by the formation of aggregate, enabling the formation of a new complex.

Sera of rabbits immunized with 15 KGy irradiated venom $(200 \mu \mathrm{g})$ toxoid neutralized venom lethality (three fold LD50). Injection of higher dose of irradiated venom $(1000 \mu \mathrm{g})$ would have had little detrimental effect on the experimental animal yet did not resulted in higher titer. or neutralizing power. In the present study, hyperimmunizing rabbits against nonirradiated, $15 \mathrm{KGy}$ and 25KGy gamma irradiated Naja haje venom, over a period of one month, yielded specific antivenin of high potency.

Using the immunodifussion experiments, non-irradiated as well as the two dose levels irradiated Naja hage venom (15 and $25 \mathrm{KGy}$ ), all showed the same pattern (Fig2,3) when tested against control antivenin, produced with non-irradiated venom and against antivenin produced with $15 \mathrm{KGy}$ irradiated venom. The four distinct visible lines, obtained in the immunodiffusion test, were identical, and joined smoothly at the corners indicating that there was no change in the antigenic determinants. The results obtained in the present work are in the agreement with those of other investigators. Sundaram et. al (1970) reported that inspite of the break down of normal human serum components in solution form after exposure to doses up to $25 \mathrm{M}$ rads (25KGy), it was able to form precipitin lines with its specific antiserum as demonstrated by polyacrlaminde gel, electrophoresis and immunodiffusioin testes

Kankonkar et al. (1975) reported that cobra venom irradiated in dry (lyophilized) form, had no changes in toxicity and antigenicity, as shown by immunodiffusion and immunoelectrophoresis with doses up to $4 \mathrm{M}$ rads (40KGy) whil for aqueous samples, the antigenicity was destroyed proportionally with the destruction of toxicity. Biloaicol .

There was no change in the titer of antivenin solution obtained from the rabbits immunized with the irradiated venom, as compared with that of antivenin solution obtained from rabbits immunized with nonirradiated Naja haje venom, using the immunodiffusion venom concentration of $20 \mathrm{mg} / \mathrm{ml}$, and serum dilution up to $1: 32$. Both groups were immunogenic and induced specific antibody formation.

Antivenom raised against $15 \mathrm{KGy}$ irradiated Naja haje venom was also found to neutralized venom lethality with the same degree (three fold $\mathrm{LD}_{50}$ ), as well as the antivenom raised against non-irradiated venom (crude venom). These results showed that antibodies generated against 
the $15 \mathrm{KGy}$ irradiated venom, were reactive towards the non-irradiated venom and viceversa showing no change in the immunogenecity.

This agree with flowers (1970) who showed that crotalied snake venom exposed to X-rays, revealed a decrease in its local reactivity $(50-70 \%)$ and an increase in the LD50, in mice (six folds). This inactivation was accompanied with little change in its antigenic character. At the same time, the antivenin produced when using $\mathrm{X}$-irradiated venom, neutralized both the local and the lethal effects of the venom. This effect was more or less, equal to that obtained with control antivenin produced when using nonirradiated venom.

However Netto et al. (2002) showed that the use of irradiated cortalus durissus terrificus venom in sheep immunization induces a powerful and lasting humoral immune response shown by both in vitro neutralization and potency tests and by indirect Elisa antibody level detection technique. Sera from the irradiated group were five times more potent than the sera from the natural group.

Protease and PLA enzymes are known to contribute to the venom toxicity or pathophysiological process(Harrivis et a $l$., 2000, Fuly et al. 2003 ), . Toxoid antivenom showed less neutralization capacity towards PLA as compared to protease activity. Gamma irradiation might have impaired the antigenic site (s) of the enzymes (PLA) molecule. Tejasen and Ottolenghi (1970), also reported that antivenom against U.V. irradiated Agkistrodon bisciveorus venom was devoid of antienzymes activity (proteinase or PLA).

Bharati and Hati (2000), immunized Rhesus monkeys (Macaca mulatto) with irradiated Russell's viper venom toxoid, without any adjuvant. The antiserum thereby raised producing approximately halfantilethal, half-antihaemorrhagic and half antinecrotic titres as compared by the commertial hyperimmunized horse antiserum. Adsorption of toxoid with suitable adjuvant may be more effective immunizing agent.

Toxoiding by gamma irradiation required much less time as compared to that of a slow and stepwise formal treatment. Salofranco (1971), reported that venom toxoid irradiated (from $60 \mathrm{co}$ ) Cobra Naja naje philippinesis, was more immunogenic as compared to untreated or formal (1\%) heated venom.

Further investigation must be done to compare antibody (raised against gamm airradiated venom toxoid ) titer and commercial antivenin on the basis of its ability to neutralize lethality and other pathopharmcaologial effects of Naja haje venom

\section{Acknowledgement}

The author would like to thank Dr. Ahmed Abdel Basset, Medical Research Center, Faculty of Medicine, Ain Shams University for his valuable help during this study.

\section{References:}

1. Alexander, P. (1960): Protection of macromolecules in vitro against damage by ionizing radiations. In: Radiation Protection and recovery, PP. 3-9 (Hollaender, A., Ed.). Oxford: Pergaman Pres.

2. Bharati, K. and Hati, A.K. (2000): Neutralization potency of gamma irradiated Russell's viper, venomtoxoid antiserum raised in rhesus monkeys, as against commercial antiserum. Indian Journal of Physiology and Allied Sciences; 54 (3): 159-64.

3. Chicheportiche R., Rochat C., Sampieri F., Lazdunski M.(1972): Structure- function relationships of neurotoxins isolated from Naja haje venom: physicochemical properties and identification of the active site. Biochemistry; 11: 1681-91.

4. Clissa, P.B.; Nascimento N. and Rogero J.R. (1999): Toxicity and immunogenicity of Crotalus durissus terrificus venom treated with different dose of gamma rays. Toxicon; 37: 1131-41.

5. Desnuelle, P.; Constantin M.J. and Baldy, J. (1995): Technique potentiometrique pour la mesure de l'activité de la lipase pancréatique. Bull. Soc. Chim. Biol. 37, 285.

6. Do-Nascimento, N.; Seebart, C.S.; Francis, B; Rogero, J.R. and Kaiser, I.I. (1996): Influence of ionizing radiation on 
crotoxin: biochemistry and immunilogical aspects. Toxicon; 34: 123-131.

7. Flowers, H.H. (1970): Problems encountered in the production of a potent antivenin. In: radiation sensitivity of toxins and animal poisons. Proceedings of a panel on the radiation sensitivity of toxins and animal poisons, organized by the IAEA and held in Banckok, PP. 95-98.

8. Freitas T.V. and Frezard F. (1997): Encapsulation of native for the production of antivenom and vaccination against Crotalus durissus terrificus venom. Toxicon; 35: 91-100.

9. Fuly, A.L., Calil-Elias, S., Martinez, P. A., Melo, P. A., and Guimaraes, J. A. (2003): Myotoxicity induced by an acidic Asp-49 phospholipase A2 isoenzymes from Micropechis ikaheka venom. Biochim. Biophys. Acta. 1545, 30-40.

10. Gene, J.A.; Gomez, M.; Gutierrez, J.M. and Cerdas, L. (1985): Neturalization of hyaluronidase and indirect hemolytic activities of costa Rican snake venoms by a polyvalent antivenom. Toxicon; 23: 10151018.

11. Guidolin R.; Diasda Silva W.; Higashi H.G.; Caricati C.P.; Lima Misr; Mora J.F.; Pinto J.R. and Marcelino J.R. (1989): Hiperimunização de cavalos soroprodutores com venenos botrópicos e crotálico tratados por glutaraldeido. Men. Inst. Butantan; 51: 85-90.

12. Harris, J.B., Grubb, B. D.,Maltin, C. A., and Dixon,R.(2000): The neurotoxicity of the venom phospholipases A2, notexin and taipoxin. Exp. Neurol., 161,517-526

13. Hati, A.K.; Hati R.N.; Mandal, M.; Panda, D. and Das, S. (1989): The effect of gamma irradiated detoxified viper venom as a toxoid against viper venom. Snake; 21, 36-40.

14. Hati, R.N.; Mandal, M. and Hati A.K. (1990): Active immunization of rabbit with gamma irradiated Russel's viper venom toxoid. Toxicon; 28: 895-902.

15. Jimenez-Porras, J.M. (1968): Pharmacology of peptides and proteins in snake venom. Ann. Rev. Pharmac; 8: 200-318.

16. Kankonkar, S.R.; Kankonkar, R.C. and Gaitonde, B.B. (1975): Irradiated Cobra (Naja naje) venom for Biomedical Applications. In: Radiosterilization of Medical Products. Proceed the ionizing radiation for sterilization of medical products and Biological Tissue, held by IAEA in Bombay, PP. 253-262.
17. Khan, Z.H.; Larifa and Ali Z. (1977): Preparation of toxoids from the venoms of Pakistan species of snakes (Naja naja, Vipera russelii and Echis carinatus). Jpn. J. Med. Sci. Biol; 30: 19-23.

18. Labib, R.S.; Awad, E.R. and Farag, N.W. (1980): Protease of Cerastes (Egyptian Sand Viper) and Cerastas (Sahara Sand Viper snake venoms). Toxicon; 19: 73-83.

19. Mandal, M.; Hati, R.N. and Hati, A.K. (1993): Neutralization of pathophysiological manifestation of Russell's viper envenoming by antivenom raised against gamma-irradiated toxioid. Toxico; 31: 213-6.

20. Moroz, C.; Goldblum, N. and Vries A. (1963): Preparation of Vipera plaestinae antineurotoxin using carboximethylcellulose-bound neurotoxin as antigen. Nature; 16: 697-8.

21. Murata, Y.; Nishikawa, A.K.; Nascimento, N.; Higashi, H.G.; Diasda Silva, W. And Rogero, J.R. (1990): Gamma irradiation reduces the toxic activities of Crotalus durissus terrificus venom does not affect their immunogenic activities. Toxicon; 28: 617-8.

22. Nascimento N. C (1996): Bioquimica e imunologica dos principais produtos gerdos irradiaçao de crotoxina. Sao Paulo: Universidade de Sao Paulo; IPEN-Inst. Pesq. Energ/ Nucl., 19-77P. ( TeseDoutorqdo)

23. Netto, D.P.; Chiacchio, S.B.; Bicudo, P.L.; Alferi, A.A. and Nascimento, N. (2002): Humoral response and neutralization capacity of sheep serum inoculated with natural and cobalt 60-irradiated crotalus durissus terrificus venom. J. Venom. Amm. Toxios. 8 (2).

24. Nieuwenhuizen, W.; Kunze, H. and De Haas, G.H. (1974): Phospholipase A2 (Phosphotide acylhydrolase. EC 3.1.14) from procine pancereas. In: Methods in enzymology, Vol. 32 PP. 147 (Flesher, S. and Packer, I.M. Eds.) New York Academic Press.

25. Ouchterlony, $O$. and Nilsson, L.A. (1978): Immunodiffusion and Immunoelectro-phoresis. In :Handbook of Experimental Immunology , $3^{\text {rd }}$ Edition, Ch.19, pp.19.23-19.28 (Weir, D.M.Ed.). Oxford: Blackwell Scientific.

26. Rocha, O.A.; Bicalho, A.F.X.; Silveira, J.N.; Lopes, E.S. and Heneine, I.F. (1992): A nontoxic derivate of Bothrops jararaca venom suitable to generate 
antibodies against the native venom. Dtsch. Tierar; Wochenschr; 99: 143-5.

27. Salafrance, E.S. (1972): Irradiation Cobra (Naja naje philippinesis) venom. Jpn. J. Med. Sci. Biol.; 25: 206.

28. Shaban, E.A. (1990): Studies on impact of irradiation treatment on pharmacological responses of scorpion venom and antivenin serum. Ph. D. Thesis, Faculty of Pharmacy, Alexandria University.

29. Shaban, E.A. (2003): Influence of ionizing radiation on (Naja haje) and Cerastes cerastes venom: Toxicological and immunological aspects. The Egyptian Journal of Hospital Medicine Vol. 13: 99-114.

30. Shaban, E.A.; Ahmed, A.A. and Hani Ayoby, M. (1996): Gamma irradiation of Egyptian Cobra (Naja haje) venom. J. Egy. Publ. Heal. Assoc. Vol. LXXI: 257-271.

31. Sundaram, K.; Sundaresan, P. and Phodke, G.P. (1970): Effect of 60 co gamma irradiation on antigen-antibody systems. In: radiation sensitivity of toxins and animal poisons. Proceeding of a panel on the radiation sensitivity of toxins and animals poisons; organized by the IAEA and held in the banckoc, PP. 13-18.

32. Tizard, L.R. (1984): In: Immunology: an introduction. Holt-Saundey International Editions. PO. 126.

33. Warrell, D.A. (1987): Animal poison. In: Manson's Tropical diseases, $19^{\text {th }} \mathrm{Ed}, \mathrm{Ch}$. 48. PP. 863 (Manson-Bahr, P.E.C. and Bell, D.R., Ed.). London: English Language Book Society/Bailliere, Tindall.

34. World Health Organization (1981): Progress in the characterization of venom; and standardization of antivenoms. Geneva: World Health Organization. Offset, pp. 23-24. 


\section{تحصين الأرانب شبه سم الكوبرا (نجا هاج) المشعع جاميا د. د. عصدت عبل السلام شعبان

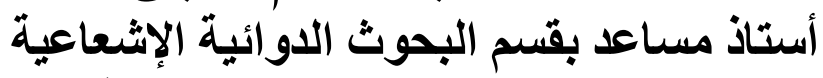 المركز القومي لبحوث وتكنولوجيا الإشعاع - هيئة الطاقة الذية الذرية}

تم تحضير مصل مضاد لسم ثعبان الكوبر ا في الأر انب بعد حقنها يشبه إنبه

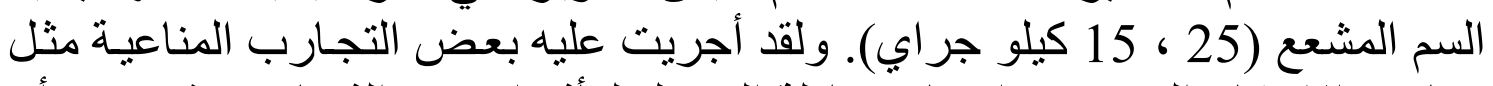

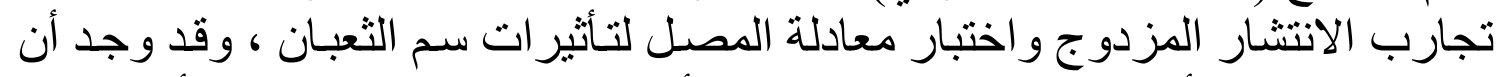

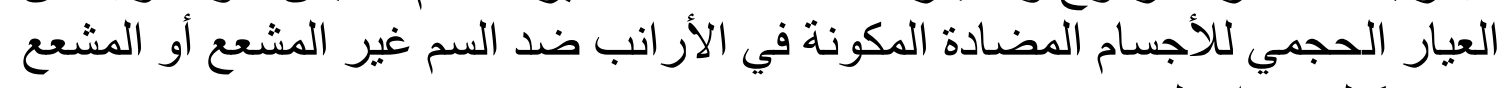

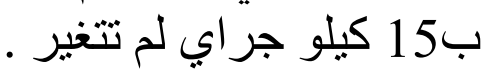

وفي تجارب الانتشـار المزدوج كون السم (غير المشعبع والمشعع ب 25 ، 15

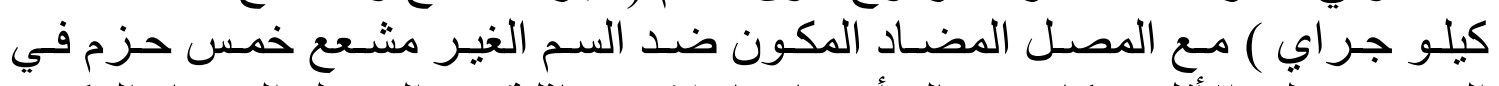

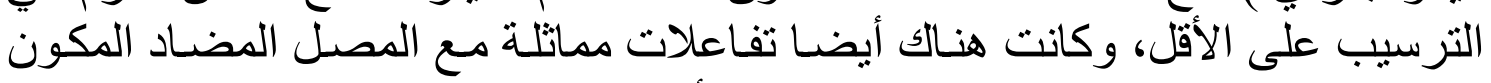

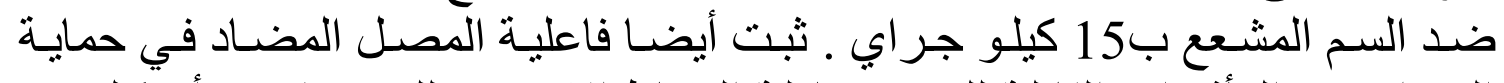

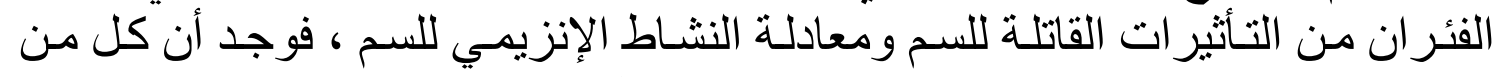

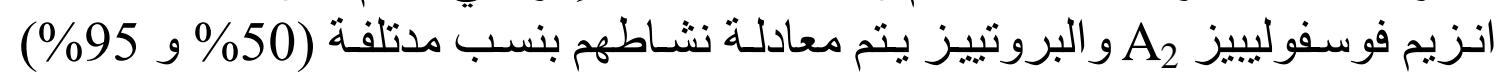
على التو الي. 